\title{
Micro-resistência no espaço urbano: um olhar sobre a dança na cidade
}

\section{Micro-resistance in urban space: a look at the dance in the city}

Débora Souto Allemand 1

Eduardo Rocha ${ }^{2}$ 


\section{Resumo}

O trabalho busca encontrar as relações que são feitas entre o espaço e o corpo e como a Arquitetura pode influenciar no movimento do corpo. Como ler a cidade corporalmente? A pesquisa tem como foco o estudo da cidade através de pesquisas de grupos de dança que a utilizam, para compreender como os diferentes espaços geram diferentes corpos e movimentos. Foram pesquisados os seguintes grupos de dança: Trisha Brown, Dani Lima, Muovere Cia. de Dança, ...AVOA! e La Casa. O trabalho propõese a chamar a atenção para os corpos e para o movimento do espaço, abrindo possibilidade para uma nova forma de projetar espaços. Assim, a arte é capaz de transgredir, possibilitando outro olhar sobre a cidade, criticando o "movimento automatizado" dos cidadãos.

Palavras-Chave: espaço urbano; dança; movimento; corpografia urbana; corpo.

\section{Abstract}

The work seeks to find relationships that are made between space and the body and how architecture can influence the movement of the body. How to read the city bodily? The research focuses on the study of the city through searches of dance groups that use it, to understand how the different spaces generate different bodies and movements. The following dance groups were studied: Trisha Brown, Dani Lima, Muovere Dance Company, ...AVOA! and La Casa. The study aims to draw attention to the bodies and the space motion, opening the possibility for a new way of designing spaces. Thus, art is able of transgressing, allowing another look over the city, criticizing the citizen automated movement.

Keywords: urban space; dance; movement; urban bodygraphy; body.

${ }^{1}$ Débora Souto Allemand 


\section{Introdução}

A cidade contemporânea é um local de constante mudança, assim como os corpos que a utilizam e se relacionam com ela. Os projetos atuais, no entanto, têm perdido sua finalidade humana e a cidade somente progride materialmente, os projetos têm sido tratados estaticamente. Segundo Gartner (1990, p. 311): "a separação filosófica entre corpo e mente resultou em generalizada ausência da experiência do corpo nas teorias do significado na arquitetura [...]". Assim, quando o corpo é pensado na arquitetura, é de modo frequentemente ergonômico. Por isso, os planejadores do espaço devem preocupar-se mais com as experiências sensoriais, "[...] nós não estamos atentos a processos, a ritmos, a fluxos, a mentalidades, a formas de experiência" (PEREIRA, 2010, p. 288). Devemos lembrar que também somos corpo.

Pensando na ideia de que a cidade proporciona diversidades, vários grupos de dança (Trisha Brown, Dani Lima, Muovere Cia de Dança, ...Avoa!, La Casa, etc.) utilizam a rua para seu processo criativo, pois entendem que o espaço físico influencia diretamente no tipo de composição que é criada. Além disso, o espaço público é democrático, proporciona o acesso de todos à arte, mostrando que o tipo de espaço influencia muito na participação do público ou não. O grupo Tá na Rua ${ }^{1}$ utiliza o espaço urbano justamente para estimular a interferência do espectador, necessitando de um alto grau de improvisação por parte dos atores (CARDOSO, 2008, p. 92), o que acarreta em diferentes obras à medida que a peça é apresentada em diferentes locais.

Um bom exemplo de que a cidade influencia diretamente no corpo de quem a utiliza é o que nos traz Paola Jacques: um morador suburbano, por exemplo, apresenta um corpo que ginga e acompanha os espaços sinuosos dos becos e ruelas. "Numa favela de morro vai-se descobrindo um ritmo de caminhar diferente, imposto pelo próprio percurso das vielas. É o que chamam de ginga." (2003, p. 66). Essa experiência corporal é definida pelo ambiente em que se insere, caracterizado por um traçado sinuoso, com critérios estéticos próprios daquele lugar. Buscando soluções para problemas imediatos, criam suas próprias regras, alternativas construtivas e de conformação dos espaços. Neste sentido, o ambiente urbano desenvolve corpos que desviam, requebram, realizam trocas, defendem valores e criam espaços únicos.

Além disso, a arte é capaz de ressignificar espaços, transformá-los em lugares de identificação, como escreve Marc Augé. "O teatro de rua contemporâneo busca significados relacionados com a percepção da perda dos espaços de encontro carac-

\footnotetext{
${ }^{1}$ Grupo de teatro de rua formado na década de 80 no Rio de Janeiro dirigido por Amir Haddad. Com o objetivo de resgatar uma expressão submersa pela cultura burguesa, utilizam o teatro como instrumento de desenvolvimento do ser humano, de conscientização de sua realidade política, social e cultural

(Grupo Tá na Rua, 2012).
} 
terística da vida contemporânea." (CARREIRA, 2007, p. 48). Assim, a pesquisa volta-se para o estudo da dança e do teatro de rua e da performance, entendendo que a arte pode abrir brechas para diferentes compreensões da cidade e é um dos meios capazes de facilitar os encontros entre as pessoas.

\section{Metodologia}

Este trabalho é de cunho qualitativo e tem como método a cartografia. Cartografia é uma metodologia experimental em cuja essência não está a validação ou a reprovação de uma situação, mas sim a possibilidade de "enxergar o não visível", de habilitar outros possíveis cenários, buscando estruturas de vínculos latentes em dimensões nem sempre questionadas pelos mapas habituais, como o instável, o frágil, o simultâneo, o não formal, o que aparece segregado, o abandonado que também é cidade e que reclama, grita aproximações (KASTRUP; PASSOS; ESCÓSSIA, 2010). A cartografia é capaz de gerar chaves interpretativas para ler os vestígios da cultura e da sociedade no espaço urbano que escapam às leituras economicistas e planificadoras da cidade oficial.

O trabalho foi realizado através de pesquisas via internet, em busca de grupos ou artistas da dança que trabalham no espaço urbano para criação coreográfica. Os grupos que realizam espetáculos na rua, cuja composição/criação é feita dentro da sala de aula, foram desconsiderados em virtude de que interessa para o trabalho compreender como o espaço é capaz de modificar o movimento corporal. Noutro momento serão analisados vídeos desses trabalhos para compreender quais são os elementos arquitetônicos e urbanos mais utilizados e como são os espaços escolhidos por estes grupos.

\section{Objetivos}

O objetivo principal do trabalho é inventariar os casos de grupos de dança que utilizam o espaço público para sua criação coreográfica, com o intuito de apurar o olhar dos Arquitetos e Urbanistas para os corpos e para o movimento do espaço, possibilitando que esses profissionais projetem as cidades de forma mais humana e sensível.

\section{Resultados e discussão}

\section{Relação entre Cidade e Corpo Contemporâneos}

A cidade contemporânea, apesar de se caracterizar como o lugar das diferenças, da diversidade racial e cultural, das conexões e das redes de fluxos, acaba cumprindo uma série de funções estabelecidas pela sociedade. Assim, as atividades que estão fora desses limites acabam questionando o que é permitido na cidade; a arte de rua rompe com essa "normalidade" da urbe, pois transgride as regras do uso espacial da cidade, recria o espaço urbano. 
Além disso, o corpo e a cidade se relacionam a partir da experiência urbana, numa condição de pertencimento mútuo - o corpo interage com o lugar e se expressa a partir da sua corporalidade. Nesse sentido, a experiência urbana fica gravada no corpo de quem a experimenta, definindo-o, mesmo que involuntariamente, o que Jacques e Brito denominam "corpografia urbana". Assim, as autoras entendem que o empobrecimento da experiência urbana gera uma restrição das possibilidades perceptivas do corpo, limitando-o (JACQUES e BRITO, 2008, p. 185).

Outro autor que trata da relação entre corpo e espaço é José Gil (2004, p. 56). Ele entende que:

Este corpo compõe-se de uma matéria especial que tem a propriedade de ser no espaço e de devir espaço, quer dizer, de se combinar tão estreitamente com o espaço exterior que daí lhe advêm texturas variadas: o corpo pode tornar-se um espaço interior-exterior produzindo então múltiplas formas de espaço [...].

Portanto, compreende-se que o corpo se modifica nos diferentes espaços em que está inserido, o que nos leva a crer que a forma como projetamos os espaços urbanos é de fundamental importância para a libertação corporal ou não.

\section{Dança e Teatro de Rua}

Uma das primeiras manifestações de Dança de Rua ocorreu em meio à crise de 1929 nos EUA, que acabou afetando o mundo quando muitos estabelecimentos foram obrigados a demitir seus funcionários para reduzir gastos. Entre esses funcionários estavam músicos e dançarinos que foram às ruas fazer shows para se sustentarem (SANTOS, 2011). Mas a explosão desse estilo de dança ocorreu na década de 70 em Nova lorque, com o movimento Hip Hop assumindo, primeiramente, forma de protesto dos jovens pobres e negros e, em seguida, ganhando espaço em outras frentes com suas diversas manifestações (SANTOS, 2011).

No Brasil, o Hip Hop inicia através do movimento Black, na década de 70. Em 1984, a Dança de Rua surgiu no centro de São Paulo, com as primeiras manifestações de b.boys na Estação São Bento do Metrô, que posteriormente passaram a acontecer na Rua 24 de Maio esquina com a Dom José de Barros, ainda no centro de São Paulo (SANTOS, 2011). Esse se tornou o principal ponto de encontro dos dançarinos de rua, abrindo assim, oficialmente, as portas do Hip Hop no Brasil, por meio da Break Dance. A dança break foi trazida pela elite brasileira que viajava para os Estados Unidos e a praticava nas casas noturnas badaladas (COLOMBERO, 2011). A partir de então, foram criados alguns grupos interessados em dialogar com o governo na busca de construção de políticas públicas voltadas para os negros, ou seja, percebe-se no espaço público e na dança, meios de incluir as minorias (RECKZIEGEL e STIGGER, 2004).

Nessa mesma época, está surgindo o Teatro de Rua, lutando pela ruptura da ordem social da cidade, denunciando a cara segregacionista do sistema no momento em que o espetáculo teatral é confinado em salas. O teatro de rua "recria o espaço 
da rua e inventa uma nova ordem, ao mesmo tempo que impõe às pessoas que caminham pela rua uma mudança: de simples pedestres a espectadores." (CARREIRA, 2007, p. 41).

Assim, a arte de rua além de se apropriar dos movimentos cotidianos como forma de aumento das possibilidades de criação, tem o caráter de movimento social, que transgride, proporcionando outra experiência urbana, além de criticar o sistema capitalista.

\section{Cidade como Espaço Cênico}

Por que e como os artistas utilizam a cidade como espaço cênico? Segundo Mendes (2012, p. 7 e 8), os artistas vão para a rua para desestabilizar as categorias de percepção do espectador em relação à arte e aos espaços físicos da cidade, causando conflitos que colocam em jogo a produção simbólica do espaço público.

Abaixo, o texto trata de alguns artistas consagrados de dança, teatro e performance que têm esse viés no seu trabalho, tentando compreender quais os elementos que eles buscam na cidade para enriquecer sua pesquisa coreográfica.

\section{Trisha Brown (Estados Unidos)}

Trisha nasceu em 1936 nos EUA e é considerada uma das fundadoras da dança pós-moderna. Suas obras foram apresentadas em locais alternativos como telhados, paredes, estruturas montadas especialmente para suas obras, tetos, colunas. $O$ destaque em suas coreografias é a utilização das ações e movimentos diários habituais, a utilização de espaços públicos alternativos que extrapolam os limites do palco, incluindo a forte característica de atenuar os limites entre a vida e a arte através da apropriação do quotidiano. A coreógrafa liberta-se dos limites da caixa cênica com intuito de ampliar as possibilidades de movimento com o corpo, além de esta $\neg$ belecer outra forma de relação com o público.

No espetáculo Walking on the wall (Caminhando na Parede), de 1971 (Figura 1), os bailarinos utilizavam equipamentos de escalada para caminhar na lateral de um edifício, obrigando os espectadores a apreciar a obra de ângulos não experimentados anteriormente (História da Dança UFPel, 2014). 


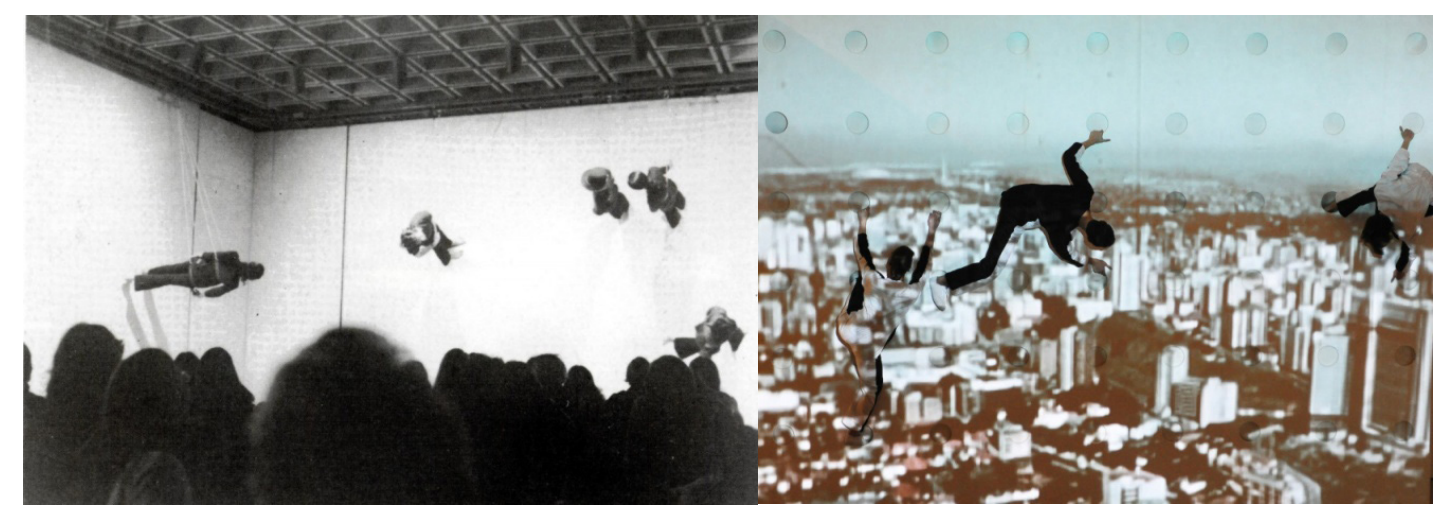

Figura 1: Espetáculo Walking on the wall, Trisha Brown. Fonte: http://bombastictelefantastic.blogspot.com.br/2011/05/laurie -anderson-trisha-brown-gordon.html. Acesso em: 06/01/14.

Em Roof Piece, de 1971 (Figura 2), Brown toma como cenário para a performance alguns telhados de Manhattan, ten $\neg$ do como pano de fundo os edifícios e o efeito escultórico das caixas d'água que compõem o skyli $\neg$ ne da região. Nesse espetáculo, o alcance do olhar é colocado em suspenso para abrir espaço para o espectador completar o desenvolvimento da performance em seu imaginário. Ao se aproximar do espaço urbano das cidades, dos movimentos cotidianos, pressupondo o corpo como intermediário de nossas rela $\neg$ ções com o mundo, a coreógrafa procura provocar uma participação ativa do observador em suas performances (DOBBERT, 2012, p. 450).

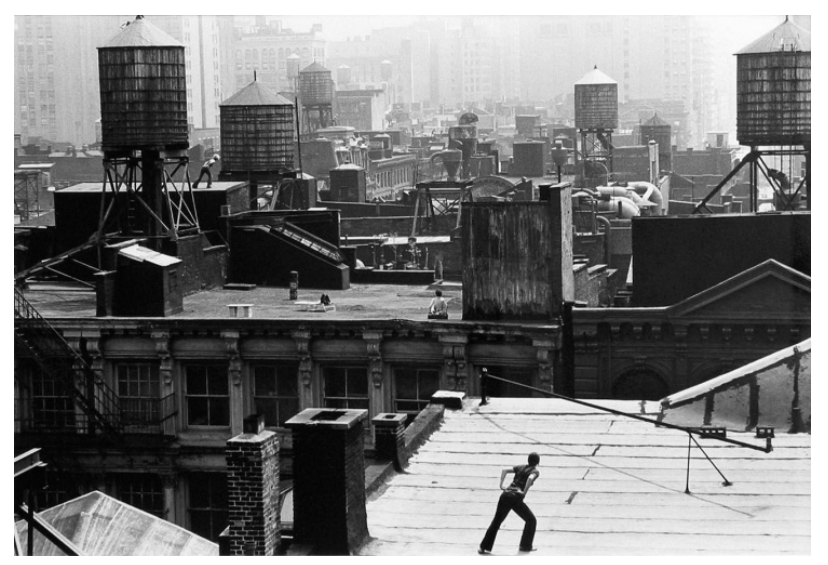

Figura 2: Espetáculo Roof Piece, Trisha Brown. Fonte: http://eesab-rennes.g-u-i.net/dnap-2-2013-2014/blog/ trisha-brown. Acesso em: 06/01/14.

Dani Lima (Rio de Janeiro - Brasil)

A bailarina e coreógrafa Dani Lima vive e trabalha no Rio de Janeiro. Foi fundadora da Intrépida Trupe e em 1997 criou sua companhia, Cia. Dani Lima, com a qual tem realizado diversos espetáculos, residências e workshops em instituições artísticas e festivais por todo Brasil e na Europa. Seu trabalho à frente de seu grupo investiga questões de identidade, alteridade, memória e percepção, investindo em experiências transdisciplinares e no desenvolvimento de uma poética do corpo cotidiano, por esse motivo trabalha bastante nos espaços públicos (Cia Dani Lima, 2014). 
A intervenção chamada Coreografia para prédios, pedestres e pombos foi um projeto realizado pela coreógrafa em parceria com a cineasta Paola Barreto no Largo do Machado (zona sul do Rio de Janeiro) em 2010. O próprio nome da intervenção remete ao que está fora do corpo bailarino: movimentos cotidianos dos prédios, pedestres e pombos, em fluxos de deslocamento e possibilidades coreográficas.

Através da interação das linguagens cinema e dança, a intervenção propõe uma remontagem dos acontecimentos no cotidiano da praça Largo do Machado. Com uma câmera instalada no alto de uma igreja e com aa comunicação por rádio, Dani Lima cria, em tempo real, a coreografia dos bailarinos em diálogo com os movimentos dos pedestres na praça. Nas coreografias camufladas, a sutileza dos movimentos cotidianos, desviados e alterados, confunde a separação entre bailarinos e pedestres (Figura 3). Assim, o lugar escolhido pelo espectador para assistir a coreografia condiciona a forma do espetáculo: na praça, ao nível do chão (próximo aos performers); no café do teatro (vendo a mixagem ao vivo das imagens e sons); na torre da Igreja (com binóculos e mp3 escolhendo seus próprios enquadramentos); ou pelo streaming via internet (MENDES, 2012, p. 11, 12 e 13). Conforme explica Dani Lima no site da Companhia, a intervenção pretende lançar um olhar atento sobre o Largo do Machado, sua arquitetura e seu paisagismo, seus frequentadores, seu cotidiano, suas memórias passadas e presentes, e contribuir para uma redescoberta do potencial poético do espaço público. Afirmar a rua como espaço de experimentação, valorizando a experiência cotidiana e a construção do comum e da comunidade como potência poética.
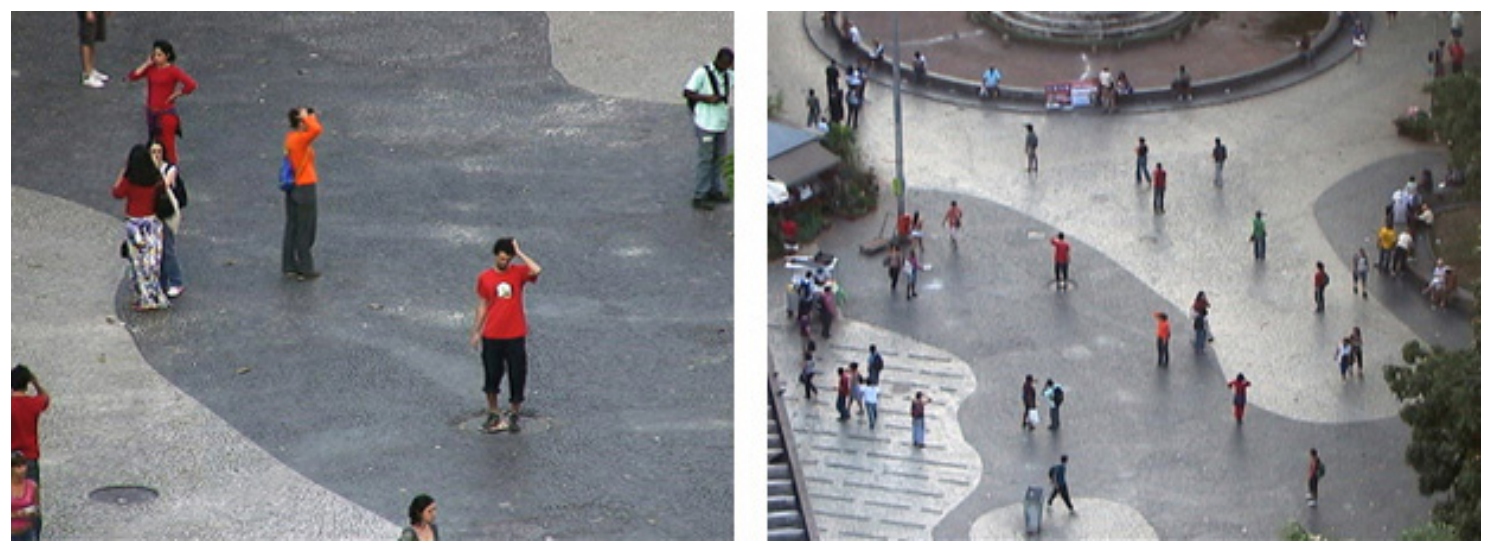

Figura 3: Coreografia para prédios, pedestres e pombos, Dani Lima. Fonte: http://www.ciadanilima.com.br/. Acesso em: 06/01/14.

\section{Muovere Cia. de Dança (Porto Alegre - Brasil)}

A Cia. Muovere foi criada em 1989 por Jussara Miranda e tem como foco a urbe como o espaço de fabricação e exibição performativa. O espetáculo Desvio Cena traduz as cenas da cidade de Porto Alegre. Os bailarinos criam células coreográficas a partir do comportamento da rua, das pessoas, dos carros, dos animais, etc. A cidade é apreendida pelo corpo dos bailarinos (Figura 4). O trabalho partiu de proposta core- 
ográfica que estuda e pesquisa os vetores de movimentação do espaço urbano, suas linhas e seus sinais, suas fluências e interdições (SANTOS, 2012).

A rota de ação da Muovere é de inclusão dos ruídos do entorno, das dificuldades do trânsito caótico, das barreiras que as massas humanas viram para o livre flanar nessa paisagem. Esse é o material das corridas (des)ordenadas dos bailarinos em cena, dos encontros ríspidos-rápidos que executam, das contorções, encaixes e desencaixes vigorosos da obra. (SANTOS, 2012).

Assim, a coreógrafa Jussara Miranda entende que não basta ir para a rua executar a dança que foi criada dentro da sala de ensaio. É necessário incorporar a rua, modificar os hábitos condicionados pelo espaço tradicional, criar/produzir a partir de outros princípios. "A partir disso, pode-se pensar numa relação de correspondência em que a dança dialogue com as histórias da cidade e suas vidas." (MIRANDA, em entrevista a Carlinhos Santos, 2013).

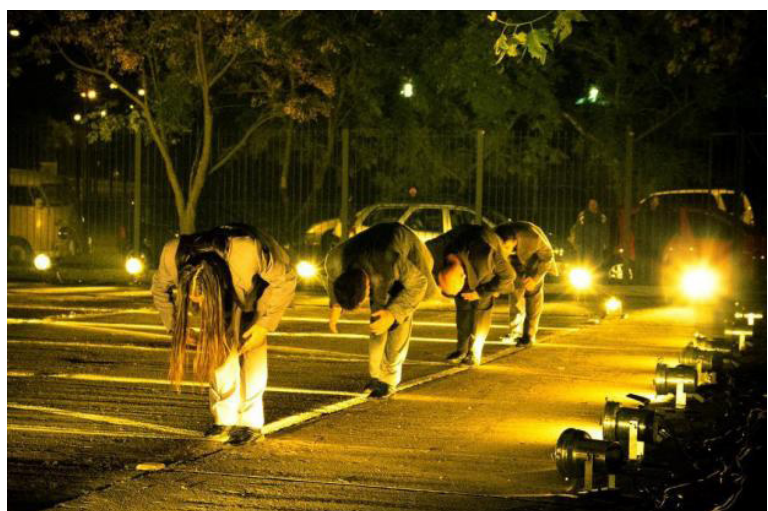

Figura 4: Espetáculo Desvio Cena, Cia. Muovere. Fonte: http://pioneiro.clicrbs.com.br/rs/cultura-e-tendencias/noticia/2013/09/muovere-danca-no-estacionamento-da-prefeitura-de-caxias-nesta-quinta-as-19h-4273352.html. Acesso em: 07/01/14.

\section{...AVOA! (São Paulo - Brasil)}

O ...AVOA! é um núcleo de dança contemporânea que desenvolve criações para espaços alternativos, como a rua. O núcleo provoca questionamentos acerca da vida urbana, criticando os movimentos automatizados do cidadão inserido na cidade, e interessa-se pelas poéticas corporais que podem surgir dos múltiplos estímulos que a rua é capaz de provocar. O grupo vai para o espaço público com o intuito de perceber as relações humanas que se estabelecem direta ou indiretamente no vai-e-vem da cidade. Os detritos, gestos e vozes, a violência, o abandono, as ruas e viadutos, as sonoridades, os fluxos e contra-fluxos, tudo isso é material de criação para o grupo, é vivenciado no corpo dos bailarinos (Figura 5). Conforme o grupo mesmo coloca, eles são "interessados na rua como território de criação e ação artística, poética, estética e política" (...Avoa!, 2014). 


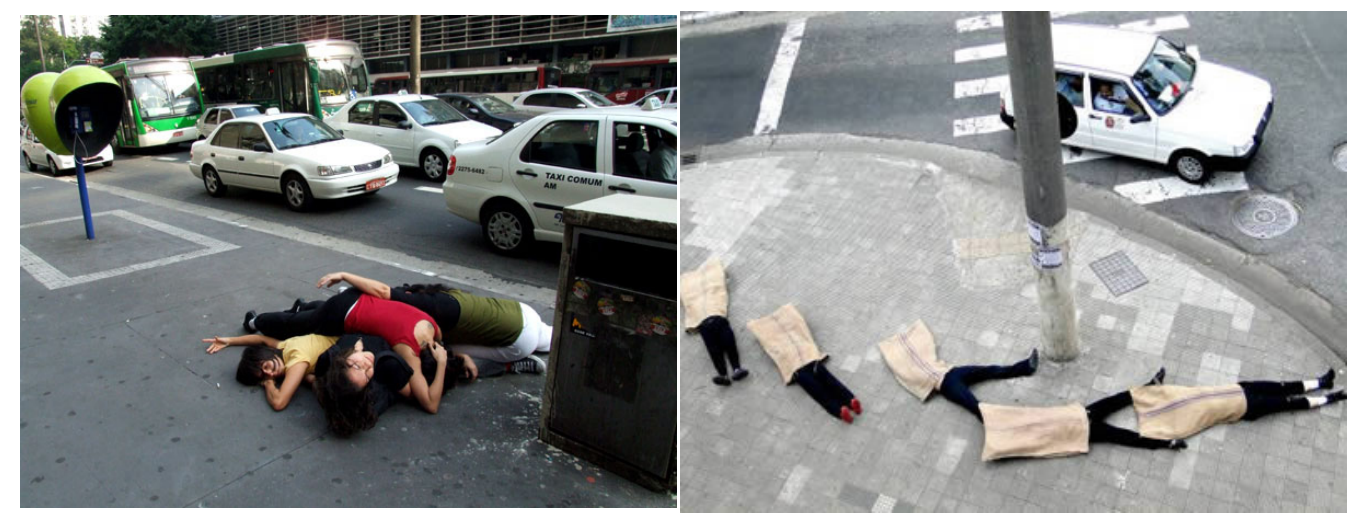

Figura 5: Espetáculo Urgência - A cidade do avesso. Fonte: http://escolaburlesca.blogspot.com.br/2010/12/cotidianovira-tema-de-espetaculo.html. Acesso em: 07/01/14.

\section{La Casa (Uruguai)}

O coletivo vem trabalhando há 7 anos, com direção geral de Mariana Marchesano. Trabalha com propostas multidisciplinares, relacionando diversas linguagens como a dança, a fotografia, o teatro, as artes visuais, a música, a arquitetura e as ciências. Os espaços utilizados pelo grupo vão desde terrenos baldios a salas de exposições, construções abandonadas, praças, etc. Suas concepções são chamadas de "obra-paisagem", questionando territórios e comportamentos, formas de viver, de habitar, de estar...

Um de seus trabalhos é o $U$, inspirado no conceito de "terrain vague" do arquiteto espanhol Solá Morales. Construiu-se a partir de um processo de investigação do movimento, do espaço e do som, seguindo a ideia de Francesco Careri sobre o andar como ação simbólica de transformação da paisagem. Os locais escolhidos são espaços intersticiais, incertos, zonas de questionamento das cidades e paisagens contemporâneas, buscando uma releitura da trama urbana. É uma busca de modificar o olhar sobre certos espaços da cidade: lugares vazios, "não produtivos" são transformados em espaços do possível. Além disso, o espectador pode estabelecer diversos vínculos com a cena, escolhendo seu próprio lugar, construindo sua própria versão do espetáculo - Figura 6 - (Proyecto La Casa, 2014).

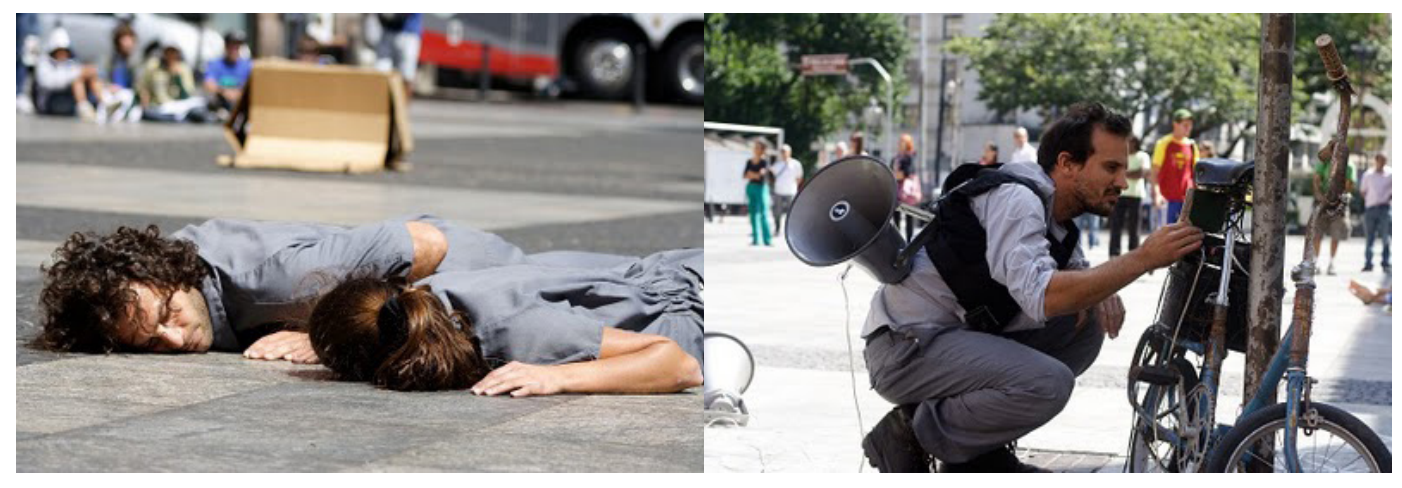

Figura 6: Espetáculo U. Fonte: http://proyectolacasa.blogspot.com.br. Acesso em: 08/01/14. 


\section{Conclusão}

A partir da coleta de dados realizada, encontramos os principais motivos que levam as companhias de dança a utilizar o espaço urbano para espetáculos e performances:

- atenuar o limite entre a vida e a arte, dialogando com a cidade;

- mostrar outra face da cidade;

- entender o potencial poético do espaço público;

- criticar os "movimentos automatizados" do cidadão;

- "aproveitar" os múltiplos estímulos da cidade (sons, fluxos, etc.).

Esses grupos que utilizam a cidade questionam quais são esses corpos que vivem no espaço urbano e qual é a coreografia de cada lugar, interferindo na cidade, mas coexistindo, acomodando-se a ela. Os bailarinos leem a cidade com seus corpos, traduzindo o que sentem a partir dos vetores de movimento da cidade, seus sinais e fluxos. A cidade está em constante movimento, portanto, como o arquiteto e urbanista pode intervir no espaço urbano sem engessá-lo? Paola Jacques, em Estética da Ginga (2003), fala sobre como intervir na favela, um espaço que está em constante transformação, mas que não é muito diferente da cidade "formal"; na favela apenas as mudanças são mais velozes que no centro.

Jacques cria, então, o conceito de Arquiteto-urbano, que teria o papel de organizar os fluxos, "seria o suscitador, o tradutor e o catalisador dos desejos dos habitantes" (JACQUES, 2003, p. 151). Assim como o artista, o arquiteto-urbano deve seguir o movimento das favelas para criar os "bairros em movimento". Segundo Jacques, ele deve atuar por outros meios para intervir nessas situações contemporâneas porque os procedimentos usuais já não abrangem mais toda a complexidade urbana (2003, p. 154).

Assim, ao final desta pesquisa consideramos que a dança pode ser um desses outros meios pelos quais o arquiteto-urbano pode trabalhar, pois a arte é capaz de construir dissensos. Esses meios são chamados de micro-resistências por Jacques (2010), atividades que são capazes de combater a lógica das cidades espetaculares, produzidas por projetos urbanos que buscam transformar os espaços públicos em cenários, espaços desencarnados. E a dança é capaz de "dar corpo" a essas cidades. 


\section{BIBLIOGRAFIA}

...AVOA! Disponível em: < http://www.nucleoavoa.com/nucleoavoa.com/quemsomos/index.html >. Acesso em: 07/01/14.

BOMBASTICTELEFANTASTIC. Disponível em: < http://bombastictelefantastic.blogspot.com.br/2011/05/laurie-anderson-trisha-brown-gordon.html >. Acesso em: 06/01/14.

CARDOSO, Ricardo José Brügger. Inter-relações entre espaço cênico e espaço urbano. In: Evelyn F. W. Lima (Org.). Espaço e Teatro: do edifício teatral à cidade como palco. Rio de Janeiro: 7Letras, 2008.

CARREIRA, André. Teatro de Rua: Brasil e Argentina nos anos 1980: Uma paixão no asfalto. São Paulo: Aderaldo \& Rothschild Editores Ltda., 2007.

CIA DANI LIMA. Disponível em: < http://www.ciadanilima.com.br >. Acesso em: 07/01/14.

CLICRBS. Disponível em: < http://pioneiro.clicrbs.com.br/rs/cultura-e-tendencias/ noticia/2013/09/muovere-danca-no-estacionamento-da-prefeitura-de-caxias-nesta-quinta-as-19h-4273352.html >. Acesso em: 07/01/14.

COLOMBERO, Rose Mary Marques Papolo. Danças Urbanas: uma história a ser narrada. FEUSP: 2011. Disponível em: http://www.gpef.fe.usp.br/teses/agenda_2011_09. pdf. Acesso em: 25/12/13.

DOBBERT, Mariana. Da Arte para a Arquitetura: As práticas de Trisha Brown, Duane Michals e Bernard Tschumi como aproximações críticas ao espaço urbano contemporâneo. VIII EHA - Encontro de História da Arte, 2012. Disponível em: < http://www. unicamp.br/chaa/eha/atas/2012/Mariana\%20Dobbert.pdf >. Acesso em: 06/01/14.

ESCOLA BURLESCA DE SÃO PAULO. Disponível em: < http://escolaburlesca.blogspot. com.br/2010/12/cotidiano-vira-tema-de-espetaculo.html >. Acesso em: 07/01/14.

GARTNER, S. The Corporeal Imagination: The Body as the Medium of Expression and Understanding in Architecture. In: The Architecture of the In-Between: The Proceedings of the 1990 ACSA Annual Conference, San Francisco, 1990.

GIL, José. Movimento Total: o corpo e a dança. São Paulo: Iluminuras, 2004.

GRUPO TÁ NA RUA. História. Disponível em: < http://www.tanarua.art.br/2011/historia-2/ >. Acesso em: 04/12/12. 
HISTÓRIA DA DANÇA UFPEL. Disponível em: < http://historiadadancaufpel.blogspot. com.br/p/coreografos-internacionais.html >. Acesso em: 07/01/14.

JACQUES, Paola Berenstein. Estética da Ginga: a arquitetura das favelas através da obra de Hélio Oiticica. Rio de Janeiro: Casa das Palavras, 2003.

JACQUES, Paola Berenstein; BRITO, Fabiana Dultra. Corpografias urbanas: relações entre o corpo e a cidade. In: Evelyn F. Werneck Lima (org.). Espaço e teatro: do edifício teatral à cidade como palco. Rio de Janeiro: 7letras, 2008.

JACQUES, Paola Berenstein. Zonas de Tensão: em busca de micro-resistências urbanas. In: Fabiana Dultra Britto; Paola Berenstein Jacques (Orgs.). Corpocidade: Debates, ações e articulações. Salvador: EDUFBA, 2010.

KASTRUP, Virgínia; PASSOS, Eduardo; ESCÓSSIA, Liliana (org.). Pistas do método da cartografia: Pesquisa-intervenção e produção de subjetividade. Porto Alegre: Sulina, 2010.

MENDES, Eloísa Brantes. Cidades Instáveis: Intervenção Artística Como Experiência Heterotópica Do Espaço Urbano. In: O Percevejo online v. 4 n². PPGAC/UNIRIO. 2012. Disponível em: < http://www.seer.unirio.br/index.php/opercevejoonline/article/view/2916 >. Acesso em: 06/01/14.

PEREIRA, Margareth da Silva. Casualidade dos Encontros. In: Fabiana Dultra Britto; Paola Berenstein Jacques (Orgs.). Corpocidade: Debates, ações e articulações. Salvador: EDUFBA, 2010. Entrevista concedida a Edu Rocha e Joubert Arrais.

PROYECTO LA CASA. Disponível em: < http://proyectolacasa.blogspot.com.br >. Acesso em: 08/01/14.

RECKZIEGEL, Ana Cecília de Carvalho; STIGGER, Marco Paulo. Dança de rua: opção pela dignidade e compromisso social. In: Revista Movimento, Porto Alegre, v. 11, n. 2, 2004.

SANTOS, Analu Silva dos. Dança de Rua: a dança que surgiu nas ruas e conquistou os palcos. 2011. Trabalho de Conclusão de Curso (Bacharelado em Educação Física), UFRGS, Porto Alegre.

SANTOS, Carlos. Muovere Desvio. Blog do Núcleo de Pesquisa em História da UFRGS. 2012. Disponível em: < http://nph-ufrgs.blogspot.com.br/2012/04/muovere-desvio. html >. Acesso em: 20/12/13. 